\begin{tabular}{|l|l|l||}
\hline \multicolumn{2}{|c|}{ PublisherInfo } \\
\hline \hline PublisherName & $:$ & BioMed Central \\
\hline \hline PublisherLocation & $:$ & London \\
\hline \hline PublisherImprintName & $:$ & BioMed Central \\
\hline \hline
\end{tabular}

\title{
Regional dissemination of VRE by interfacility transfer
}

\begin{tabular}{||l|l|l||}
\hline \multicolumn{2}{|c||}{ ArticleInfo } \\
\hline \hline ArticleID & $:$ & 4153 \\
\hline \hline ArticleDOI & $:$ & $10.1186 /$ ccf-1999-2041 \\
\hline \hline ArticleCitationID & $:$ & 2041 \\
\hline \hline ArticleSequenceNumber & $:$ & 12 \\
\hline \hline ArticleCategory & $:$ & Paper Report \\
\hline \hline ArticleFirstPage & $:$ & 1 \\
\hline \hline ArticleLastPage & $:$ & 3 \\
\hline \hline & & RegistrationDate : 1999-10-18 \\
ArticleHistory & $:$ & OnlineDate $\quad$ 1999-10-18 \\
\hline \hline ArticleCopyright & $:$ & Current Science Ltd1999 \\
\hline \hline ArticleGrants & $:$ & \\
\hline \hline ArticleContext & $:$ & 1305422 \\
\hline \hline
\end{tabular}




\section{Keywords}

epidemiology, infection, Vancomycin-resistant enterococci

\section{Comments}

This is an interesting study in that it demonstrates how alarming quickly VRE can disseminate itself around medical facilities. What is unclear from the paper is exactly what sort of facility is referred to as a LTCF. Only one of the 28 facilities had the ability to ventilate patients. If these facilities are providing a similar environment to UK nursing homes then the implications are that these facilities may provide a reservoir of VRE infection within the UK.

\section{Introduction}

Between 1989 and 1996 the proportion of enterococci noted to be vancomycin resistant in the US National Noscomial Infections Surveillance system increased from $0.3 \%$ to $14.2 \%$. Part of the problem is that patients, once colonised remain so for long periods of time, thus providing a reservoir of infection. The role of patient transfer between facilities in spreading infection had not been previously studied. This study conducted a point prevalence survey of all health care facilities in the Siouxland District Health department (SDHD) region and evaluated the role of interfacility transfer in spreading VRE.

\section{Aims}

To assess the prevalence of VRE, determine the risk factors for patient acquision of VRE and to assist the development of a regional VRE prevention and control programme.

\section{Methods}


Patients in four acute care facilities (ACFs) and 28 long term care facilities (LTCFs) were included in the survey. Two of the four ACFs had ICU facilities; the LTCFs are described as "skilled care facilities" and one had long term ventilated patients. Swabs were collected from all eligible patients over three days. Two different microbiological tests were used for the detection of VRE. A case control study was then performed comparing the cases with VRE to matched controls from the same establishment without VRE colonisation. Antimicrobial use, underlying diagnosis and previous VRE colonisation were ascertained to evaluate risk factors for infection.

\section{Results}

Swabs were obtained from 152 of 286 ACF patients (53\%) and 1782 of 1980 LTCF patients (90\%). A total of 44 patients were positive for VRE. Four of these samples were not confirmed as VRE, and were excluded from subsequent analysis. All 40 VRE isolates were Enterococcus faecium. VRE prevalence was significantly higher in the ACFs compared to the LTCFs (6.6\% vs $1.7 \%$ OR 4.1). At least one VRE colonised patient was found in three of four ACFs, and 12 of 28 LTCFs. Cases in the control study, were more likely to have been hospitalised in an ACFs in the preceeding 6 months and to have had a shorter stay in the LTCF. Cases were also more likely to have been transferred from another region, received antimicrobial drugs or to have had a GI bleed although these differences were not satistically significant. There was a geographical association of infection with different strains.

\section{Discussion}

The data demonstrates that within seven months of the first case of VRE being reported, VRE had spread to many institutions. Most of the residents of LTCFs colonised with VRE had recently been in ACFs. VRE transmission in ACFs can be prevented by appropriate isolation procedures, hand washing and the wearing of gowns. It remains to be seen how effective and appropriate these measures are in LTCFs. One limitation of the study was the poor response rate by ACF patients. However, one unit with high VRE infection rates had a good response rate and, conversely, had all the non responders been VRE negative the rate in ACFs would still have been higher than LTCFs.

\section{References}

1. Trick WE, Kuehnert MJ, Quirk SB, Arduino MJ, Aguero SM, Carson LA, Hill BC, Banerjee SN, Jarvis WR: Regional dissemination of Vancomycin-resistant enterococciresulting from interfacility transfer of colonized patients. J Infect Dis . 1999, 180: 391-396. 